\title{
In Vitro Regeneration of Cephalotus follicularis
}

Chia-Yun Ko

Institute of Bioinformatics and Structural Biology and Department of Life Science, National Tsing Hua University, No. 101, Sec. 2, Kuang Fu Road, Hsinchu, 30013, Taiwan; and Institute of Plant and Microbial Biology, Academia Sinica, Taipei, 11529, Taiwan

Tsai-Yun Lin ${ }^{1,3}$ Institute of Bioinformatics and Structural Biology and Department of Life Science, National Tsing Hua University, No. 101, Sec. 2, Kuang Fu Road, Hsinchu, 30013, Taiwan

\section{Chin-Wen Ho}

Department of Bioengineering, Tatung University, Taipei, 10452, Taiwan

\section{Jei-Fu Shaw ${ }^{2,3}$}

Department of Food Science and Biotechnology, National Chung Hsing University, Taichung, 40227, Taiwan; and Institute of Plant and Microbial Biology, Academia Sinica, Taipei, 11529, Taiwan

Additional index words. insectivorous plant, plant regeneration, plant hormone, shoot proliferation, nutrient element content

\begin{abstract}
To establish a mass micropropagation procedure for Cephalotus follicularis, the effects of varying the strengths of solid Murashige and Skoog (MS) medium were investigated using subcultured shoot explants. After a 60-day primary culture from root mass, the regenerated shoot explants were subcultured every 60 days in solid MS medium. To facilitate shoot proliferation, liquid MS medium was applied with or without exogenous auxin and cytokinin. Our results demonstrate that shoot proliferation and survival of $C$. follicularis is most effective in modified MS (MMS) medium containing onefifth or one-tenth strength macronutrients and full-strength micronutrients. Successful shoot proliferation and development of $C$. follicularis explants were obtained in one-fifth or one-tenth modified liquid MS medium without auxin and cytokinin or with addition of $5 \mu \mathrm{M}$ indole 3-acetic acid/1 $\mu$ M N6-benzyladenine for 45 days. The liquid medium consistently produced more explants than the solid medium and shortened the culturing time. Plantlets cultured in hormone-free one-fifth MMS medium developed greater root systems. Using the liquid culture we established, vigorous plants with extensive roots were obtained within 4 months. Plant survival in the greenhouse reached $100 \%$.
\end{abstract}

Carnivorous plants can live in soil with low levels of mineral nutrients (Lowrie, 1998), because most species obtain a substantial nutrient supply by trapping and digesting insects and small animals. Carnivory has been documented in at least nine families and $\approx 500$ species in the world (Lowrie, 1998). The carnivorous Venus fly trap (Dionaea muscipula Ellis), which belongs to the monotypic genus Dionaea of the Droseraceae family, is a peren-

Received for publication 1 July 2009. Accepted for publication 3 Dec. 2009.

This work was supported by National Science Council grants NSC 97-2317-B-007-001 and NSC 95-2317-B-001-001.

We thank Professor Hui-Nien Hung for statistical advice, Professor Shu-Hua Chien for providing help on nutrient element analysis, and Cindy Buschena for critical reading of the manuscript.

${ }^{1}$ Professor.

${ }^{2}$ President.

${ }^{3}$ To whom reprint requests should be addressed; e-mail tylin@life.nthu.edu.tw; presid@dragon.nchu. edu.tw. nial plant indigenous to bogs in coastal areas of North and South Carolina and has also been introduced in Florida (Culham and Gornall, 1994). Micropropagation allows the production of a large number of plants and is a useful tool for producing carnivorous plants and their byproducts. For example, naphthoquinones, which are traditional remedies for dry and irritating coughs, can be produced and extracted from cell suspensions and in vitro cultures of Venus fly trap (Hook, 2001). Stable in vitro plantlet regeneration of the Venus fly trap has been achieved using floral stalk explants (Teng, 1999), and an in vitro micropropagation method was established by shoot culture (Jang et al., 2003). Pinguicula lusitanica L., a rare insectivorous plant with pharmacological value and limited reproductive capacity, was also efficiently propagated in vitro (Goncalves et al., 2008). Propagation of Nepenthes khasiana Hooker, an endangered medicinal plant and the only insectivorous pitcher plant of India, was propagated through enhanced axillary branching in vitro (Latha and Seeni, 1994).
Adams et al. (1979) described a method for propagation of Cephalotus follicularis by shoot tip culture and increased clonal multiplication using half-strength Linsmaier-Skoog (LS) medium (Linsmeier and Skoog, 1965).

Cephalotus is a genus of flowering plants belonging to the monotypic family Cephalotaceae. Cephalotus follicularis Labill., an attractive insectivorous plant endemic to southwestern Australia, has two leaf forms: simple lanceolate leaves and developed pitchers. The flower of $C$. follicularis has six ovateelliptic sepals, 12 filaments with mauve stamens, and six pale green flask-like ovaries (Lowrie, 1998). The haploid chromosome number of $C$. follicularis is uniform $(\mathrm{n}=10)$ regardless of population or habitat (Keighery, 1979). Cephalotus is an outbreeding perennial but grows slowly and takes many years to reach flowering age. Propagation through seed is slow, and seed stratification is required. Cephalotus follicularis can be regenerated from sections of root mass, a characteristic used by horticulturists for vegetative propagation; however, the number of plantlets that can be produced this way is limited. Plant tissue culture is a powerful tool for propagation of rare species, yet only a few studies of $C$. follicularis tissue culture have been reported. In the propagation of the $C$. follicularis explants, half-strength liquid LS medium resulted in a 10-fold increase in a 6-month period (Adams et al., 1979). The LS medium contains the same macroelements as the Murashige and Skoog (MS) medium but only has supplements of $100 \mathrm{mg} \cdot \mathrm{L}^{-1}$ myoinositol and $0.4 \mathrm{mg} \cdot \mathrm{L}^{-1}$ thiamine $\mathrm{HCl}$ (Linsmeier and Skoog, 1965). The goal of this study was to develop an effective method of mass micropropagation of $C$. follicularis.

\section{Materials and Methods}

Plant material and primary culture. An in vitro culture of $C$. follicularis was generated using a plant purchased from an agricultural market in Taiwan. To generate a primary culture, segments of root mass were surfacesterilized with $75 \%(\mathrm{v} / \mathrm{v})$ ethanol for $30 \mathrm{~s}$ and a $0.15 \%$ sodium hypochlorite solution for $30 \mathrm{~min}$. After thoroughly rinsing with sterile double-distilled water, the root segments were cultivated and shoot explants were generated within $60 \mathrm{~d}$ culture in a modified MS (MMS) basal medium (Murashige and Skoog, 1962) containing one-tenth strength macroelements and full-strength microelements of MS salts supplemented with myoinositol $\left(100 \mathrm{mg} \cdot \mathrm{L}^{-1}\right)$, nicotinic acid (1 $\left.\mathrm{mg} \cdot \mathrm{L}^{-1}\right)$, pyridoxine $\mathrm{HCl}\left(1 \mathrm{mg} \cdot \mathrm{L}^{-1}\right)$, thiamine $\mathrm{HCl}\left(10 \mathrm{mg} \cdot \mathrm{L}^{-1}\right)$, sucrose $\left(20 \mathrm{~g} \cdot \mathrm{L}^{-1}\right)$, phyto agar $\left(8 \mathrm{~g} \cdot \mathrm{L}^{-1}\right)$, and with no plant hormone. The $\mathrm{pH}$ of this modified medium (one-tenth MMS medium) was adjusted to 5.7 with $0.1 \mathrm{~N} \mathrm{KOH}$ and $\mathrm{HCl}$ before autoclaving for $20 \mathrm{~min}$ at $121{ }^{\circ} \mathrm{C}$. The shoot explants were maintained by periodic subculture in this medium in $40 \times 150-\mathrm{mm}$ culture tubes under a 16-h light/8-h dark photoperiod at $22 \pm 1{ }^{\circ} \mathrm{C}$ with light irradiance of 32 to $36 \mu \mathrm{mol} \cdot \mathrm{m}^{-2} \cdot \mathrm{s}^{-1}$ for $60 \mathrm{~d}$. 
Modification of the Murashige and Skoog medium strength. The MS basal medium was modified with different strengths (1, half, one-fifth, and one-tenth) of macroelements and full-strength microelements of MS salts. All other supplements, as previously described, were added into each of the media and adjusted to $\mathrm{pH} 5.7$ before autoclaving. Explants obtained from the primary culture were subcultured into $600-\mathrm{mL}$ culture flasks for $60 \mathrm{~d}$ under the same growth conditions. Each treatment consisted of three replicate flasks, each with 10 to 13 explants. At the end of $60 \mathrm{~d}$, shoot proliferation was evaluated to obtain percent survival. Survival was recorded when explants remained green and proliferated, whereas failure to survive was recorded when explants turned brown and stopped growing.

Chlorophyll content measurement. Samples, each containing four shoot explants $(\approx 0.35 \mathrm{~g})$, were collected from MS media of different strengths, weighed, quickly frozen in liquid nitrogen, and stored at $-80{ }^{\circ} \mathrm{C}$ before analysis. The experiment was replicated three times. Each sample was homogenized in 1.0 $\mathrm{mL}$ of $80 \%(\mathrm{v} / \mathrm{v})$ acetone using a pestle in an Eppendorf tube. After removing cellular debris by centrifugation, the supernatant containing chlorophyll was diluted $1: 10(\mathrm{v} / \mathrm{v})$ with $100 \%(\mathrm{v} / \mathrm{v})$ acetone in a $15-\mathrm{mL}$ tube. Absorption at 663 and $646 \mathrm{~nm}$ was measured for each sample using a spectrophotometer. Chlorophyll concentrations were calculated as follows: chlorophyll concentration $\left(\mathrm{mg} \cdot \mathrm{mL}^{-1}\right)=$ chlorophyll $a(12.5 \times \mathrm{A} 663-2.25 \times \mathrm{A} 646)+$ chlorophyll $b(18.29 \times$ A646-4.58 $\times$ A663 $)$ (Hanfrey et al., 1996). Total chlorophyll content $\left(\mathrm{mg} \cdot \mathrm{g}^{-1}\right)$ was calculated as chlorophyll concentration $\left(\mathrm{mg} \cdot \mathrm{mL}^{-1}\right) \times$ volume $(\mathrm{mL}) /$ fresh weight of sample (g).

Establishment of liquid culture. The modified liquid MS (MLMS) medium contained one-fifth or one-tenth strength macroelements and full-strength microelements of MS salts supplemented with myoinositol $\left(100 \mathrm{mg} \cdot \mathrm{L}^{-1}\right)$, nicotinic acid $\left(1 \mathrm{mg} \cdot \mathrm{L}^{-1}\right)$, pyridoxine $\mathrm{HCl}(1$ $\left.\mathrm{mg} \cdot \mathrm{L}^{-1}\right)$, thiamine $\mathrm{HCl}\left(10 \mathrm{mg} \cdot \mathrm{L}^{-1}\right)$, sucrose (20 g. $\left.\mathrm{L}^{-1}\right)$, and 2-(N-morpholino)ethanesulfonic acid (MES) $\left(500 \mathrm{mg} \cdot \mathrm{L}^{-1}\right)$. The medium contained MES to maintain a stable $\mathrm{pH}$. Each sample of $2.0 \mathrm{~g}$ explant from the primary culture was subcultured in $30 \mathrm{~mL}$ one-tenth MLMS medium without plant hormone in a $125-\mathrm{mL}$ conical flask on an orbital shaker at $120 \mathrm{rpm}$ under a 16-h light/8-h dark photoperiod at $22 \pm 1{ }^{\circ} \mathrm{C}$ with light irradiance of 26 to $28 \mu \mathrm{mol} \cdot \mathrm{m}^{-2} \cdot \mathrm{s}^{-1}$ for $45 \mathrm{~d}$. To examine the effects of MS strength and hormone condition on C. follicularis shoot proliferation, different amounts of indole 3-acetic acid (IAA) and N6benzyladenine (BA) were applied. Each sample of subcultured explant $(2.0 \pm 0.1 \mathrm{~g})$ was cultured in one-fifth MLMS or one-tenth MLMS medium with four different conditions of plant hormones, including no IAA/BA, 1 $\mu \mathrm{M}$ IAA $/ 1 \mu \mathrm{MBA}, 1 \mu \mathrm{M}$ IAA/ $5 \mu \mathrm{MBA}$, and 5 $\mu \mathrm{M}$ IAA $/ 1 \mu \mathrm{M}$ BA. IAA and BA were filtered through $0.22-\mu \mathrm{m}$ Millipore MCE membrane (Millipore Corp., MA) and added to the sterile MLMS medium. After $45 \mathrm{~d}$ in liquid culture, explants were harvested and weighed. Each treatment had three replicates.

Rooting and acclimatization. After subculture for $45 \mathrm{~d}$ in one-fifth MLMS medium, multiple shoots were divided into single plantlets and grown in one-fifth MMS solid medium without plant hormone to induce adventitious roots in a growth chamber under a 16-h light/8-h dark photoperiod at 25 to $28{ }^{\circ} \mathrm{C}$ with light irradiance of 56 to 60 $\mu \mathrm{mol} \cdot \mathrm{m}^{-2} \cdot \mathrm{s}^{-1}$. After $60 \mathrm{~d}$, plantlets with adventitious roots were removed from the medium and washed gently with tap water. Plantlets were then grown in pots with sphagnum moss and covered with transparent plastic bags to maintain high humidity for 2 weeks in a growth chamber for acclimation.

Analysis of nutrient contents. Explants cultured in various strengths of MS media for $30 \mathrm{~d}$ were harvested and dried in an oven at $180{ }^{\circ} \mathrm{C}$ for $4 \mathrm{~h}$. The carbon, hydrogen, and nitrogen elemental analysis was performed using each dried sample of $2 \mathrm{mg}$ on a FlashEA CHN 1112 analyzer (Thermo Electron Corporation, MA). Each sample of $5 \mathrm{mg}$ dried explants was extracted in $3 \mathrm{~mL}$ acidic buffer [1/4 (v/v) $\mathrm{HNO}_{3}$ and $\left.3 / 4(\mathrm{v} / \mathrm{v}) \mathrm{HCl}\right]$ with a high-pressure container at $110{ }^{\circ} \mathrm{C}$ for $1 \mathrm{~h}$. After cooling down, $5 \mathrm{~mL}$ of $0.6 \mathrm{M} \mathrm{H}_{3} \mathrm{BO}_{3}$ was added and the solution was collected

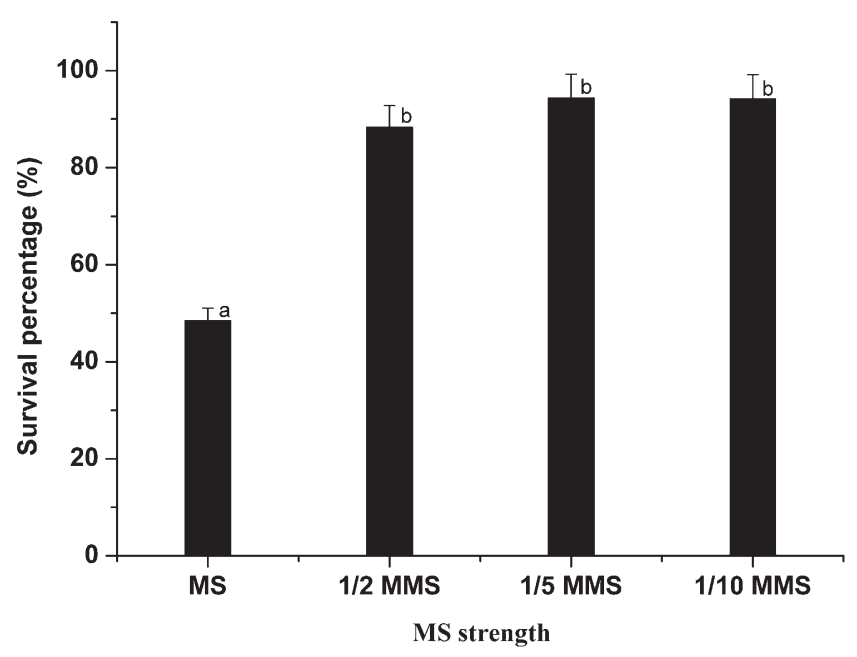

Fig. 1. Effects of Murashige and Skoog (MS) medium concentrations on regeneration of C. follicularis. Survival percentages of explants in various MS medium concentrations were monitored after $60 \mathrm{~d}$ of culture. Values in each graph column followed by different letters are significantly different $(P<0.05)$ according to one-way analysis of variance. The mean \pm SD values of the survival percentages $(\%)$ of explants in MS, half-strength modified MS (MMS), one-fifth MMS, and one-tenth MMS medium are $48.5 \pm 2.6,88.4 \pm 4.4,94.4 \pm 4.9$, and $94.2 \pm 5.0$, respectively.

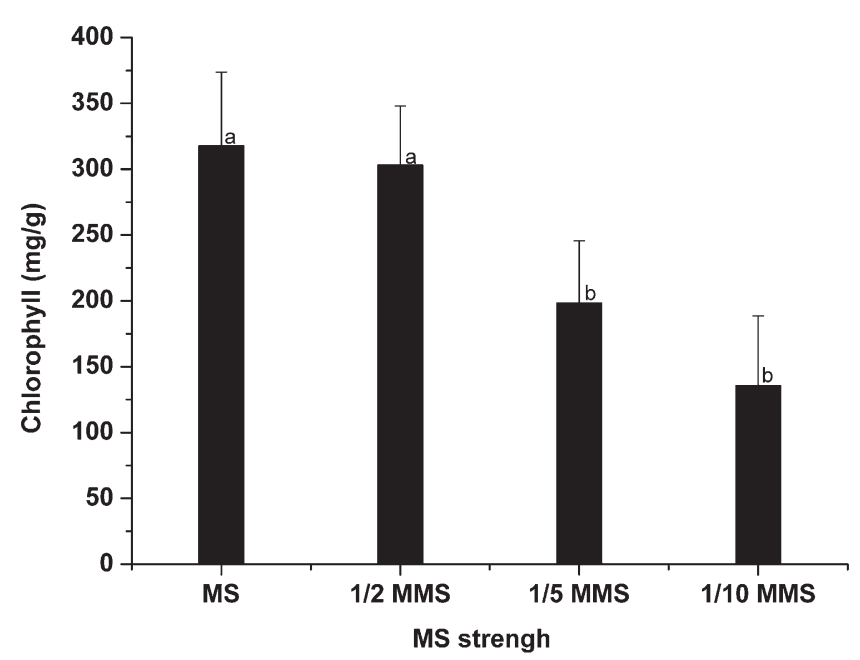

Fig. 2. Effects of Murashige and Skoog (MS) medium concentrations on chlorophyll accumulation in regenerated explants of $C$. follicularis. The chlorophyll content of explants in various MS medium concentrations was monitored after $60 \mathrm{~d}$ of culture. Values in each graph column followed by different letters are significantly different $(P<0.05)$ according to one-way analysis of variance. The mean $\pm \mathrm{SD}$ values of the chlorophyll contents ( $\mathrm{mg} \cdot \mathrm{g}^{-1}$ fresh weight) of explants in MS, half-strength modified MS (MMS), one-fifth MMS, and one-tenth MMS medium are 317.7 $\pm 56.1,303.1 \pm 44.9,198.6 \pm 46.9$, and $135.8 \pm 52.7$, respectively. 
through filter paper. The solution was adjusted to a final volume of $25 \mathrm{~mL}$ with sterile water to measure potassium, calcium, and magnesium elements using a Z-8200 polarized Zeeman atomic absorption spectrophotometer (Hitachi Ltd., Tokyo, Japan).

Statistical analysis. The effects of various MS medium concentrations on the survival percentages and chlorophyll contents of explants were analyzed with one-way analysis of variance (ANOVA) to assess treatment differences. Effects of IAA and BA on liquid culture of $C$. follicularis were subjected to twoway ANOVA assay. Differences among treatment means were analyzed with parameter estimation to fit a model using the free statistical software R (http://www.r-project.org).

\section{Results}

A primary culture of $C$. follicularis was established after incubation of explants from segments of root mass in one-tenth MMS medium for $60 \mathrm{~d}$. The explants were stably maintained by subsequent subculture in onetenth MMS medium. Our results demonstrate that shoot proliferation of $C$. follicularis explants is greatly influenced by the strength of the MS medium (Fig. 1). Higher survival was observed in half-strength MMS medium (88.4\%) or one-fifth MMS (94.4\%) or onetenth MMS medium (94.2\%) than in MS (48.5\%, $P<0.05)$. Shoot explants cultured in full- or half-strength MS always displayed darker green color than that in one-fifth or one-tenth MMS. We found that the strength of the MS medium affected explant chlorophyll content (Fig. 2). Explants cultured in MS or half-strength MMS medium had a much higher chlorophyll content $(317.7 \mathrm{mg}$ or $303.1 \mathrm{mg}$ ) compared with those cultured in one-fifth MMS or one-tenth MMS medium (198.6 mg or $135.8 \mathrm{mg}, P<0.05$ ). Leaves of explants cultured in full-strength MS medium became dark green and then turned brown and wilted. Moreover, an accumulation of brownish spots was observed in the MS and half-strength MMS medium. Leaves of explants cultured in one-fifth MMS or onetenth MMS medium were green and developed normally. Our data indicated that explants cultured in one-fifth MMS or onetenth MMS medium grew better than those in MS or half-strength MMS medium.

The chlorophyll contents of explants cultured for $30 \mathrm{~d}$ (Fig. 3) were similar to those cultured for $60 \mathrm{~d}$ (Fig. 1). Explants cultured for $30 \mathrm{~d}$ in MS or half-strength MMS contained higher nitrogen content based on dry mass $\left(63.98\right.$ or $\left.65.36 \mu \mathrm{g} \cdot \mathrm{mg}^{-1}\right)$ than that in one-fifth MMS medium (59.85 $\left.\mu \mathrm{g} \cdot \mathrm{mg}^{-1}\right)$, which is higher than that in one-tenth MMS medium (48.23 $\mu \mathrm{g} \cdot \mathrm{mg}^{-1}$; Table 1). The decrease of $80 \%$ macronutrient from MS to one-fifth MMS resulted in an $8 \%$ decrease of nitrogen content in explants. The potassium content of explants was higher in MS medium $\left(49.59 \mu \mathrm{g} \cdot \mathrm{mg}^{-1}\right)$ than in half-strength MMS or one-fifth MMS or one-tenth MMS medium (Table 1). An 80\% macronutrient decrease resulted in a $32 \%$ decrease of potassium in explants. However, the same macronutrient decrease resulted in an increase in magnesium $(30 \%)$ and calcium ( $8 \%)$ in explants (Table 1$)$. Carbon content in explants cultured in onefifth MMS was slightly higher (1\%) but hydrogen was lower $(2 \%)$ than that in MS.

After primary culture, the explants subcultured on solid medium generally take $60 \mathrm{~d}$

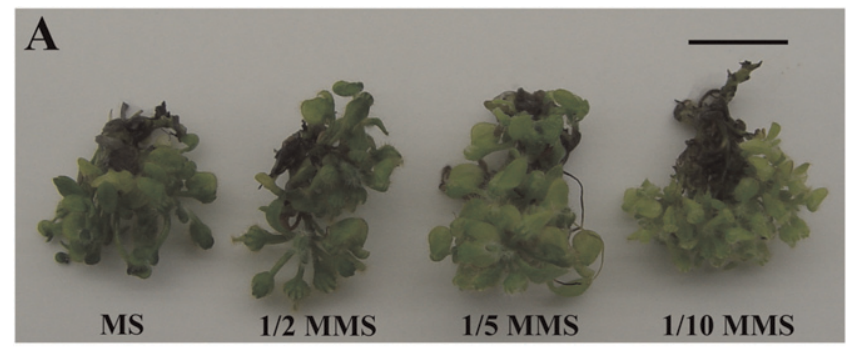

B

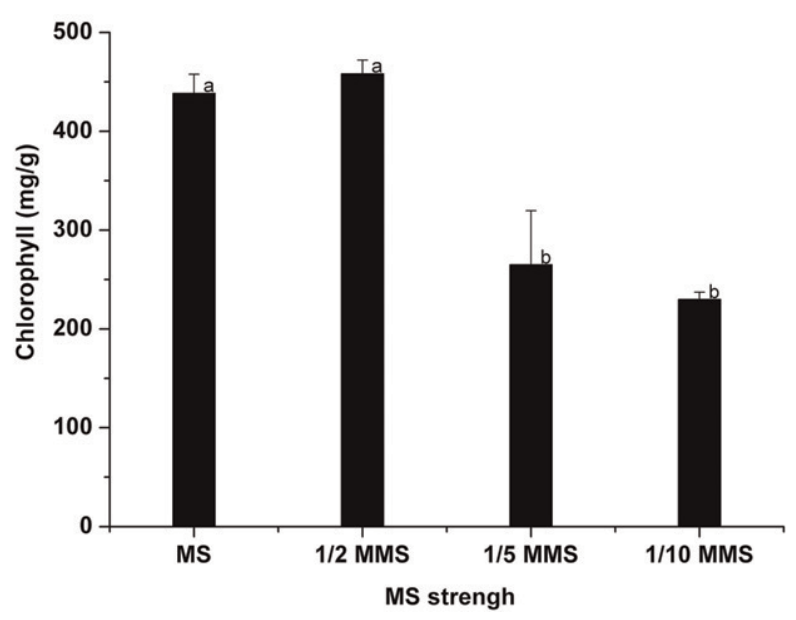

Fig. 3. Effects of Murashige and Skoog (MS) medium concentration on growth (A) and chlorophyll accumulation $(\mathbf{B})$ of $C$. follicularis explants in various strength of MS media for $30 \mathrm{~d}$. Values in each graph column followed by different letters are significantly different $(P<0.01)$ according to one-way analysis of variance. Bar $=1 \mathrm{~cm}$.

Table 1. Mean nutrient contents \pm SD of $C$. follicularis explant cultured in various strengths of modified Murashige and Skoog (MMS) mediums for $30 \mathrm{~d}{ }^{\mathrm{z}}$

\begin{tabular}{|c|c|c|c|c|c|c|}
\hline MS strength & $\begin{array}{l}\text { Nitrogen } \\
\left(\mu g \cdot \mathrm{mg}^{-1}\right)\end{array}$ & $\begin{array}{l}\text { Carbon } \\
\left(\mu g \cdot \mathrm{mg}^{-1}\right)\end{array}$ & $\begin{array}{l}\text { Hydrogen } \\
\left(\mu g \cdot \mathrm{mg}^{-1}\right)\end{array}$ & $\begin{array}{l}\text { Potassium } \\
\left(\mu \mathrm{g} \cdot \mathrm{mg}^{-1}\right)\end{array}$ & $\begin{array}{l}\text { Magnesium } \\
\left(\mu g \cdot \mathrm{mg}^{-1}\right)\end{array}$ & $\begin{array}{l}\text { Calcium } \\
\left(\mu g \cdot \mathrm{mg}^{-1}\right)\end{array}$ \\
\hline$\overline{\mathrm{MS}}$ & $63.98 \pm 1.91^{\mathrm{a}}$ & $477.07 \pm 2.70^{b}$ & $57.74 \pm 0.94^{\mathrm{a}}$ & $49.59 \pm 0.24^{\mathrm{a}}$ & $1.82 \pm 0.02^{\mathrm{c}}$ & $6.65 \pm 0.07^{b}$ \\
\hline $\begin{array}{l}\text { Half-strength } \\
\text { MMS }\end{array}$ & $65.36 \pm 0.58^{a}$ & $476.04 \pm 3.62^{b}$ & $56.97 \pm 0.56^{\mathrm{ab}}$ & $35.79 \pm 0.25^{\mathrm{b}}$ & $1.47 \pm 0.02^{\mathrm{d}}$ & $6.56 \pm 0.04^{\mathrm{c}}$ \\
\hline One-fifth MMS & $59.85 \pm 1.34^{\mathrm{b}}$ & $480.81 \pm 1.60^{\mathrm{ab}}$ & $55.63 \pm 0.64^{\mathrm{b}}$ & $33.67 \pm 0.19^{\mathrm{c}}$ & $2.37 \pm 0.02^{\mathrm{b}}$ & $7.17 \pm 0.03^{\mathrm{a}}$ \\
\hline One-tenth MMS & $48.23 \pm 0.73^{\mathrm{c}}$ & $481.74 \pm 0.76^{\mathrm{a}}$ & $55.16 \pm 0.89^{\mathrm{b}}$ & $29.33 \pm 0.20^{\mathrm{d}}$ & $2.80 \pm 0.02^{\mathrm{a}}$ & $6.35 \pm 0.03^{\mathrm{d}}$ \\
\hline \multicolumn{7}{|c|}{$\begin{array}{l}\text { zContents of nitrogen, carbon, and hydrogen elements were measured with the FlashEA } 1112 \text { analyzer } \\
\text { (Thermo Electron Corp.) and potassium, magnesium, and calcium were measured with an atomic } \\
\text { absorption spectrophotometer. All the measurements were based on dry weight of explants. } \\
\text { yThe different superscript letters in the same column represent significant difference }(P<0.05) \text { in the } \\
\text { nutrient content. }\end{array}$} \\
\hline \multicolumn{7}{|c|}{$\begin{array}{l}\text { Table 2. Effects of Murashige and Skoog (MS) strength and hormone conditions on modified liquid MS } \\
\text { culture of explants analyzed by two-way analysis of variance. }{ }^{z}\end{array}$} \\
\hline Source & Sum & of square & $\begin{array}{l}\text { Degrees of } \\
\text { freedom }\end{array}$ & Mean square & $\mathrm{F}$ & $P$ value \\
\hline Hormone conditic & & 9.977 & 3 & 6.659 & 7.603 & 0.0004 \\
\hline MS strength & & 0.037 & 1 & 10.037 & 11.460 & 0.0016 \\
\hline Interaction & & 2.492 & 3 & 0.831 & 0.948 & 0.4265 \\
\hline Error & & 5.034 & 40 & 0.876 & & \\
\hline Total & & 7.539 & 47 & & & \\
\hline
\end{tabular}

${ }^{\mathrm{z}}$ No interaction was found between the two factors, namely, MS strength and hormone condition. 
Table 3. Comparison of the effects of Murashige and Skoog (MS) strength and hormone condition on the growth of C. follicularis explants in modified liquid MS (MLMS) culture. ${ }^{z}$

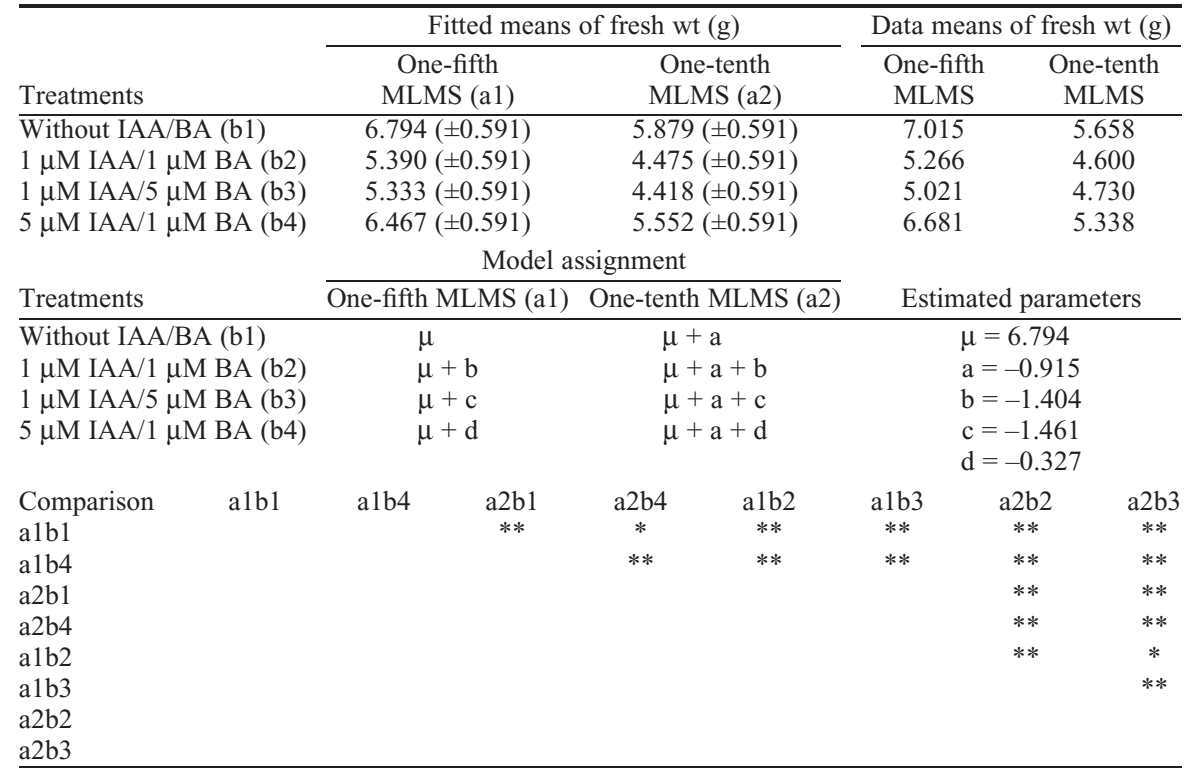

${ }^{2}$ Each sample contained $2 \mathrm{~g}$ starting explants at $0 \mathrm{~d}$. Fresh weights (mean \pm confidence interval) of the explants were measured after $45 \mathrm{~d}$ of culture. The fitted mean was calculated with a model and estimated parameters using the free statistical software R. The one-fifth and one-tenth MLMS media are indicated by "a1 " and "a2" and the four hormone conditions are "b1" to "b4." In the model, parameter $\mu$ is the mean of alb1; parameter $\mathrm{a}$ is the effect of change from a1 to a2; parameters b, c, and d are the effects of changes from b1 to b2, b1 to b3, and $\mathrm{b} 1$ to $\mathrm{b} 4$, respectively. Differences between each two treatments are shown in the comparison matrix. $*$,**Statistically significant differences of $P<0.05$ and $P<0.01$, respectively.

IAA $=$ indole 3-acetic acid; $\mathrm{BA}=$ N6-benzyladenine.

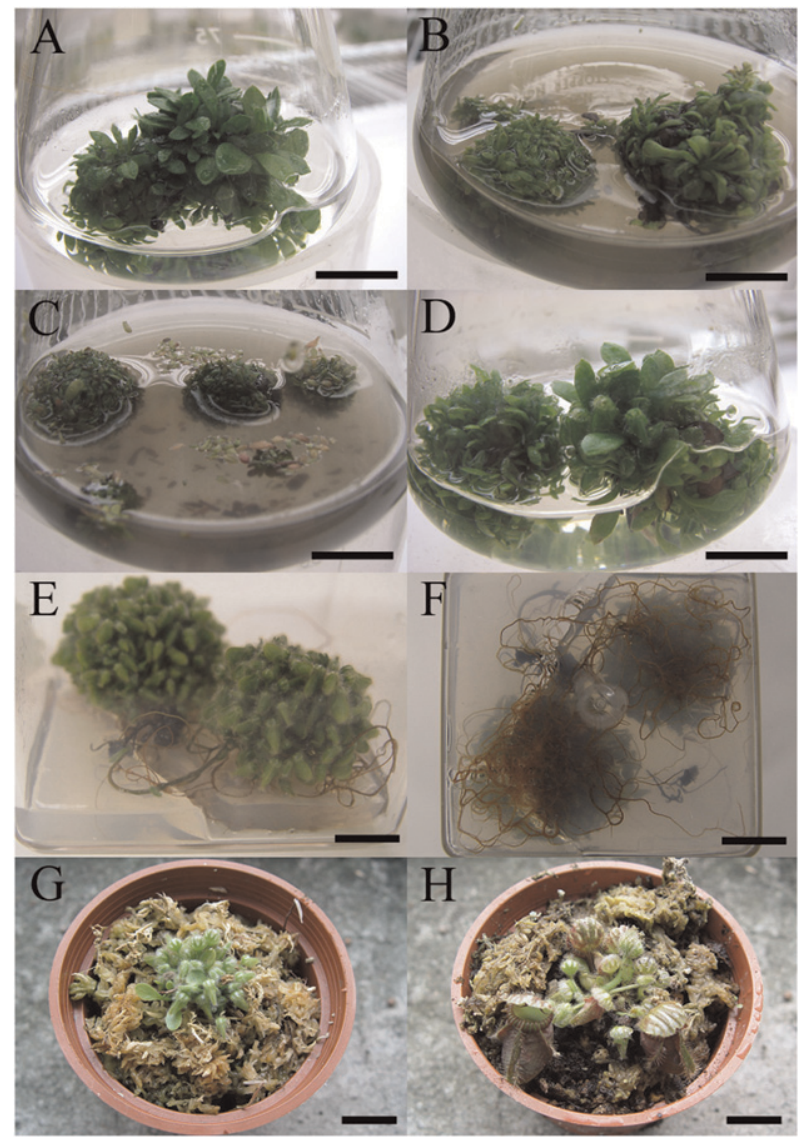

Fig. 4. Shoot proliferation and plant regeneration of $C$. follicularis. Shoot morphology of $C$. follicularis cultured in one-fifth modified liquid Murashige and Skoog medium without indole 3-acetic acid (IAA) and N6-benzyladenine (BA) (A) and with $1 \mu \mathrm{M} \mathrm{IAA} / 1 \mu \mathrm{M}$ BA (B), $1 \mu \mathrm{M} \mathrm{IAA} / 5 \mu \mathrm{MBA}(\mathbf{C})$, and $5 \mu \mathrm{M}$ IAA/1 $\mu$ M BA (D) for 45 d. (E-F) Side and bottom views of the adventitious roots after 8 weeks culture. (G-H) Plants grown on sphagnum moss for 2 and for 6 months. Bar $=1 \mathrm{~cm}$.
ANOVA was applied to analyze the effects of MS strength and hormone condition on C. follicularis shoot proliferation; no interaction was found between the two factors, namely, MS strength and hormone condition (Table 2). Thus, the effect of each treatment was compared using a model without an interaction term to fit the treatment means. Table 3 describes the treatment conditions, fitted means, data means, model assignment, parameters estimation, and a comparison matrix showing the significance of differences between treatments at $P<0.05$ or 0.01 . Successful shoot proliferation and normal development of $C$. follicularis explants were obtained without exogenous auxin and cytokinin (Fig. 4A) or with the addition of $5 \mu \mathrm{M}$ IAA/1 $\mu \mathrm{M}$ BA (Fig. 4D). Under these conditions, shoot explants exhibited more vigorous growth and fresh weight increased from $2.00 \mathrm{~g}$ to $6.79 \mathrm{~g} \pm 0.59$ (mean \pm confidence interval) in hormone-free medium and to $6.47 \mathrm{~g} \pm 0.59$ (mean \pm confidence interval) with the addition of $5 \mu \mathrm{M}$ IAA $/ 1 \mu \mathrm{M}$ BA (Table 3). Fresh weights of shoot explants grown in media with $1 \mu \mathrm{M}$ IAA/ $1 \mu \mathrm{M}$ BA (Fig. 4B) or with $1 \mu \mathrm{M}$ IAA $/ 5 \mu \mathrm{M}$ BA (Fig. 4C) were $5.39 \mathrm{~g} \pm 0.59$ or $5.33 \mathrm{~g} \pm$ 0.59 (Table 3). The liquid medium remained clear during the $45 \mathrm{~d}$ in culture, suggesting only a few or no phenolic compounds secreted from explants. Liquid medium containing $1 \mu \mathrm{M}$ IAA $/ 1 \mu \mathrm{M}$ BA (Table 2; Fig. 4B) or $1 \mu \mathrm{M}$ IAA/5 $\mu \mathrm{M}$ BA (Table 2; Fig. 4C) was less effective for shoot proliferation and the medium turned a brown or dark brown color after 2 weeks, indicating secretion of phenolic compounds from the explants. A significant difference $(P<$ 0.05 ) in effectiveness was found between the one-fifth MLMS and one-tenth MLMS medium (Table 2). The effects of exogenous auxin and cytokinin were similar in onefifth MLMS and one-tenth MLMS medium (Table 2).

Multiple shoots were divided into single plantlets after subculture for $45 \mathrm{~d}$ in one-fifth MLMS medium; the separated shoots produced extensive root systems in one-fifth MMS solid medium without plant hormone after culturing $60 \mathrm{~d}$ (Fig. 4E-F). Plantlets were transferred to pots containing sphagnum moss after washing with tap water to remove residual agar. During an acclimation period of 2 weeks in a growth chamber, the plants were covered with transparent plastic bags to ensure high humidity. The growth chamber was maintained at 25 to $28^{\circ} \mathrm{C}$ with a 16 -h light/ 8 -h dark photoperiod of 56 to $60 \mu \mathrm{mol} \cdot \mathrm{m}^{-2} \cdot \mathrm{s}^{-1}$ light irradiance. Four weeks after transfer to the greenhouse, survival reached $100 \%$ and plants exhibited vigorous growth (Fig. 4G-H). The proliferation rate of shoot explants was 3.5fold in one-fifth MLMS medium (from $\approx 2 \mathrm{~g}$ to $\approx 7 \mathrm{~g}$ ) and twofold in one-fifth MMS medium (from $\approx 2 \mathrm{~g}$ to $\approx 4 \mathrm{~g}$ ). Thus, the proliferation of shoot in liquid medium produced 18.8 -fold as many explants of solid medium in a 6-month period (Table 4, Step 2A versus 2B). This study describes an efficient protocol for mass propagation of $C$. follicularis. 
Table 4. An efficient protocol for mass propagation of C. follicularis.

\begin{tabular}{|c|c|c|}
\hline Step & Procedure & Time course and proliferation rate \\
\hline 1 & $\begin{array}{l}\text { Establishment of the primary culture: } \\
\text { explants were obtained from segments } \\
\text { of rootstock in one-tenth MMS medium }\end{array}$ & $\begin{array}{l}\text { Primary culture of explants was established } \\
\text { after } 60 \mathrm{~d} \text { incubation }\end{array}$ \\
\hline $2 \mathrm{~A}$ & $\begin{array}{l}\text { Shoot propagation in liquid medium: } \\
\text { explants were subcultured in one-fifth } \\
\text { or one-tenth MLMS without hormone } \\
\text { or with the addition of } 5 \mu \mathrm{M} \\
\text { IAA } 1 \mu \mathrm{M} \mathrm{BA}\end{array}$ & $\begin{array}{l}\text { Explants in MLMS were subcultured every } \\
45 \mathrm{~d} \text {; with the proliferation rate of } \\
3.5 \text {-fold (from } 2 \mathrm{~g} \text { to } 6.68 \text { to } 7.01 \mathrm{~g} \text {, Table } 2 \text { ), } \\
\text { explants in MLMS increased } 150 \text {-fold in a } \\
\text { period of } 6 \text { months }\left(3.5^{4}=150 \text { ) }\right.\end{array}$ \\
\hline $2 \mathrm{~B}$ & $\begin{array}{l}\text { Shoot propagation in solid medium: } \\
\text { explants were subcultured in } \\
\text { one-fifth MMS or one-tenth MMS } \\
\text { medium without hormone }\end{array}$ & $\begin{array}{l}\text { Explants in MMS were subcultured every } 60 \mathrm{~d} \text {; } \\
\text { with the proliferation rate of twofold (from } \\
2 \mathrm{~g} \text { to } 4 \mathrm{~g} \text {, Fig. 1), explants in MMS increased } \\
\text { eightfold in } 6 \text { months }\left(2^{3}=8\right)\end{array}$ \\
\hline 3 & $\begin{array}{l}\text { Root induction: adventitious roots were } \\
\text { induced by culturing shoot explants on } \\
\text { one-fifth MMS without hormone. }\end{array}$ & $\begin{array}{l}\text { The root system was well developed at } 60 \mathrm{~d} \\
\text { after culturing in one-fifth MMS }\end{array}$ \\
\hline 4 & $\begin{array}{l}\text { Acclimation of plantlets: plantlets were } \\
\text { transferred to pots and acclimatized } \\
\text { in a growth chamber }\end{array}$ & $\begin{array}{l}\text { The acclimation process for the plantlets } \\
\text { was } 2 \text { weeks in a growth chamber }\end{array}$ \\
\hline 5 & $\begin{array}{l}\text { Maturation of plants: plantlets were } \\
\text { grown in natural environment }\end{array}$ & $\begin{array}{l}\text { Plantlets were transferred to a greenhouse } \\
\text { and reached mature stage in } \approx 1 \text { year }\end{array}$ \\
\hline
\end{tabular}

\section{Discussion}

Our results show that $C$. follicularis grows poorly in full-strength MS medium (Fig. 1; $P<0.05)$, which is reasonable given that carnivorous plants appear adapted to grow in soils with a low nutrient content, particularly nitrogen. Other studies have had similar results, for example floral stalk explants of Venus fly trap were more successfully induced in half-strength MS medium (same as half-strength MMS in this article) than in MS medium (Teng, 1999), and shoot proliferation was more effective in onethird MS or one-sixth MS medium than in MS medium (Jang et al., 2003). It has also been reported that shoot proliferation of $C$. follicularis was better in half-strength LS medium than in full-strength LS medium (Adams et al., 1979). In our C. follicularis culture, the half-strength MMS or one-fifth MMS or one-tenth MMS medium provided better shoot proliferation than MS medium (Fig. 1). Our results agree with previous findings (Adams et al., 1979; Goncalves et al., 2008; Jang et al., 2003; Teng, 1999) that the macroelement content of the growing medium should be reduced to cultivate vigorous carnivorous plants. The hormone-free one-fifth or one-tenth MLMS medium is sufficient to effectively propagate vigorous shoot explants; this application significantly lowered the nutrient requirement and increased the shoot proliferation rate of $C$. follicularis (Table 4).

Nitrogen content of MS medium was five times that of one-fifth MMS medium. Yet nitrogen content of explants in one-fifth MMS medium was only $8 \%$ lower than that in MS medium, indicating that the insectivorous plant $C$. follicularis obtained sufficient macronutrients in one-fifth MMS medium. Although slightly decreased with reducing supply, potassium content of explants in onefifth MMS medium was only $32 \%$ lower than that in MS medium. In our study, magnesium and calcium content of explants in one-fifth MMS medium was 30\% and $8 \%$ higher than that in MS medium, respectively, indicating an efficient uptake of nutrients by $C$. follicularis. The one-fifth MMS medium was the best medium for $C$. follicularis culture based on survival and nutrient content data (Figs. 1 and 3; Table 1).

Reduced growth in plantlets was caused by exogenous application of $1 \mu \mathrm{M} \mathrm{IAA} / 1 \mu \mathrm{M}$ BA (Fig. 4B) and $1 \mu \mathrm{M}$ IAA $/ 5 \mu \mathrm{M}$ BA (Fig. $4 C)$. Abnormality of the explants persisted even after transferring to hormone-free medium and culture for 4 months. However, $\mu \mathrm{M}$ IAA/1 $\mu \mathrm{M}$ BA. Apparently, exogenous application of plant hormones is not required for $C$. follicularis tissue culture. plantlets grew normally with the addition of 5
Explants cultured on MS or half-strength MMS initially appeared dark green and then turned brown and wilted, suggesting that the full-strength MS nutrients might have overloaded the plant system with some of the essential nutrients like nitrogen and potassium and cause plant death as a consequence. Thus, the nutrients provided by one-fifth or one-tenth MMS are sufficient for plantlet growth during early stages of propagation in vitro. Our results lead to the conclusion that hormone-free onefifth MLMS or one-tenth MLMS medium is the most effective suspension medium for $C$. follicularis micropropagation.

\section{Literature Cited}

Adams, R.M., S.S. Koenigsberg, and R.W. Langhans. 1979. In vitro propagation of Cephalotus follicularis (Australian pitcher plant). HortScience 14:512-513.

Culham, A. and R.J. Gornall. 1994. The taxonomic significance of naphthoquinones in the Droseraceae. Biochem. Syst. Ecol. 22:507-515.

Goncalves, S., A.L. Escapa, T. Grevenstuk, and A. Romano. 2008. An efficient in vitro propagation protocol for Pinguicula lusitanica, a rare insectivorous plant. Plant Cell Tissue Organ Cult. 95:239-243.

Hanfrey, C., M. Fife, and V. BuchananWollaston. 1996. Leaf senescence in Brassica napus: Expression of genes encoding pathogenesisrelated proteins. Plant Mol. Biol. 30:597-609.

Hook, I.L.I. 2001. Naphthoquinone contents of in vitro cultured plants and cell suspensions of Dionaea muscipula and Drosera species. Plant Cell Tissue Organ Cult. 67:281-285.

Jang, G.W., K.S. Kim, and R.D. Park. 2003. Micropropagation of Venus fly trap by shoot culture. Plant Cell Tissue Organ Cult. 72:95-98.

Keighery, G.J. 1979. Chromosome counts in Cephalotus (Cephalotaceae). Plant Syst. Evol. 133: 103-104.

Latha, P.G. and S. Seeni. 1994. Multiplication of the endangered Indian pitcher plant (Nepenthes khasiana) through enhanced axillary branching in-vitro. Plant Cell Tissue Organ Cult. 38:69-71.

Linsmeier, E.M. and F. Skoog. 1965. Organic growth factor requirements of tobacco tissue cultures. Physiol. Plant. 18:100-127.

Lowrie, A. 1998. Carnivorous plant of Australia. Vol. 3. University of Western Australia Press, Nedlands, Western Australia.

Murashige, T. and F. Skoog. 1962. A revised medium for rapid growth and bio assays with tobacco tissue cultures. Physiol. Plant. 15:473-497.

Teng, W.L. 1999. Source, etiolation and orientation of explants affect in vitro regeneration of Venus fly trap (Dionaea muscipula). Plant Cell Rep. 18:363-368. 